\title{
PERCEPÇÃO DOS ESTUDANTES DO ENSINO MÉDIO ACERCA DO PROFISSIONAL CONTÁBIL ${ }^{1}$
}

\author{
PERCEPTION OF HIGH SCHOOL STUDENTS \\ ABOUT THE ACCOUNTING PROFESSIONAL
}

\author{
Nadielli Maria dos Santos Galvão ${ }^{2}$ \\ Mestra em Ciências Contábeis pela Universidade Federal de Pernambuco (UFPE) \\ Professora da Faculdade de Ciências Humanas de Pernambuco (SOPECE) \\ profa.nadielligalvao@gmail.com
}

\section{RESUMO}

O ensino médio no Brasil é marcado pelo processo de escolha profissional por parte dos adolescentes e jovens. Sabe-se que para fazer essa escolha diversos fatores sociais, familiares e psicológicos são analisados. Dentre as diversas áreas disponíveis como opção, tem-se a contabilidade como alternativa. Sendo assim, o objetivo deste estudo foi verificar como estudantes do ensino médio, prestes a escolherem o curso universitário, percebem o profissional contábil. Para o alcance deste objetivo, realizou-se uma pesquisa survey com discentes de uma escola pública localizada na cidade de Jaboatão dos Guararapes/PE. Os resultados apontam que os entrevistados entendem que o contador realiza atividades como cálculos dos impostos, análise de custos, elaboração de folha de pagamento e declaração do imposto de renda. Ressalta-se que 79,46\% dos respondentes consideram o contador importante para o desenvolvimento do país, bem como para $63,39 \%$ dos estudantes o profissional da área contábil é capaz de ajudar o governo a aplicar bem os impostos, ao mesmo tempo que $47,32 \%$ dos estudantes apontaram que o contador pode ajudar a diminuir a corrupção no país.

Palavras-chave: Contabilidade; Ensino Médio; Escolha Profissional.

\section{ABSTRACT}

The high school in Brazil is marked by the professional selection process by adolescents and youth. It is known that to make that choice several social, psychological and family are analyzed. Among the various areas available as an option, you have the accounting instead. Thus, the aim of this study was to determine how high school students about to choose the university course realize the accounting professional. To achieve this objective, we carried out a survey research with students of a public school in the city of Jaboatão dos Guararapes/PE. The results show that respondents understand that the counter performs activities such as calculations of taxes, cost analysis, preparation of payroll and tax returns. It is noteworthy that $79.46 \%$ of respondents consider the accountant is important for the development of the country, as well as $63.39 \%$ of students the professional

\footnotetext{
${ }^{1}$ Artigo recebido em: 26/05/2016. Revisado por pares em: 05/07/2016. Versão final recebida em: 14/07/2016. Recomendado para publicação em: 17/07/2016 por Luiz Felipe de Araújo Pontes Girão (Editor Adjunto). Publicado em: 24/08/2016. Organização responsável pelo periódico: UFPB.

2 Endereço: Av. João de Barros, 561, CEP 50.050-180, Recife/PE.

DOI: http://dx.doi.org/10.18405/recfin20160203
} 
accounting area is able to help the government implement the taxes and at the same time that $47.32 \%$ of students indicate that the accountant can help reduce corruption in the country.

Keywords: Accounting; High Scholl. Professional Choice.

\section{INTRODUÇÃO}

Sabe-se que o período de escolha profissional no Brasil se inicia em uma fase da vida cercada de dúvidas e incertezas, onde além destes aspectos, o jovem percebe-se muitas vezes pressionado a escolher uma carreira que possa alinhar segurança à realização pessoal e profissional (JORDANI et al., 2014). Sendo assim, nesse período, diversos critérios auxiliam o processo de escolha de qual profissão seguir. Estudos anteriores apontam que família, amigos, interesses pessoais, mercado de trabalho entre outros são adotados como norteadores para a escolha profissional dos jovens. Outro fator importante é que a maioria dos jovens escolhem profissões que estejam ligadas a certo prestígio social, tais como direito, medicina e engenharia (VALORE; CAVALLET, 2012; AQUINO, 2015; TOKARNIA, 2015).

No entanto, apesar da área contábil apresentar um crescimento significativo nos últimos anos (COTRIN; SANTOS; ZOTTE JÚNIOR, 2012), esta não tem sido apontada significativamente como uma opção para os estudantes do ensino médio (VALORE; CAVALLET, 2012; AQUINO, 2015; TOKARNIA; 2015). Diante disso, torna-se relevante perceber qual a imagem que os alunos que estão prestes a realizar vestibular possuem do contador e se esta imagem pode exercer influência no que tange a escolher ou não a profissão como uma carreira a seguir, culminando assim no seguinte objetivo para este estudo: verificar a percepção de estudantes do ensino médio, prestes a escolher o curso universitário, quanto ao profissional contábil.

Outros estudos foram realizados com objetivos semelhantes ao do presente trabalho, tais como Azevedo (2010), Longo, Meurer e Oliveira (2014), Curty e Tavares (2014) e Roth et al. (2015), que, de modo geral, apresentam que para diversos grupos sociais, o contador possui uma imagem positiva. Em contraponto, tem-se o estudo de Cory (1992), que no contexto norte-americano apontou um estereótipo negativo do contador entre estudantes universitários. Ainda de acordo com Cory e Martinez (2010), esse imaginário negativo pode explicar a relutância que muitos jovens possuem de escolher essa área profissional. No entanto, outros estudos internacionais tais como, Germanou, Hassall e Tournas (2009) e Wessels e Steenkamp (2009) apresentam seus resultados mais alinhados aos apresentados pelos estudos nacionais.

Ainda no que se refere aos estudos anteriores, tem-se os trabalhos de Miranda, Miranda e Araújo (2013) e Nunes et al. (2014) que averiguaram que os estudantes de ensino médio não possuem conhecimento das reais atividades do contador, no entanto, essa falta de informação não diminui o prestígio que os mesmos atribuem ao profissional. Por outro lado, o estudo de Malthus e Fower (2009) apontou que a ausência de uma informação embasada quanto ao trabalho exercido pelo profissional contábil exerce influência negativa na percepção que os estudantes possuem sobre o contador.

No entanto, dos demais trabalhos realizados no âmbito nacional, nenhum avaliou a percepção dos estudantes quanto ao papel social do contador, no que se refere ao combate à corrupção, também no que tange ao contador ser capaz de ajudar o governo a aplicar de forma mais justa os impostos cobrados, bem como outros aspectos que inserem o profissional contábil como um ator ativo do cenário social. Estudar estes aspectos se torna ainda mais relevante visto que Brasil é conhecido como um dos maiores cobradores de impostos do mundo ao mesmo tempo que aplica muito mal os valores arrecadados (ECONOMIA UOL, 2012), bem como foi palco, em 2015, do maior escândalo de corrupção no mundo, caso que foi apelidado de Petrolão, investigado pela operação Lava Jato (CHADE, 2015). 
Além desta introdução, o artigo segue na segunda seção com a revisão da literatura que aborda os conceitos necessários para uma completa compreensão do trabalho. A terceira seção aponta a metodologia de pesquisa aplicada para o alcance do objetivo proposto. A quarta seção apresenta e discute os resultados da pesquisa e por último, na quinta seção é apresentada a conclusão do estudo, suas limitações e sugestões para futuras pesquisas.

\section{REVISÃO DE LITERATURA}

\subsection{Escolha Profissional}

Com a aproximação da conclusão do ensino médio, descortina-se diante do adolescente uma nova realidade: a escolha profissional e a definição de um curso superior. O curso escolhido será, possivelmente, aquele que irá responder às suas necessidades pessoais, sociais e econômicas (EHRLICH; CASTRO; SOARES, 2000). Assim, o jovem ingressa no ensino superior cheio de expectativas e planos, podendo, no entanto, deparar-se com uma escolha equivocada, passando a viver uma crise pessoal em uma época em que se esperava encontrar sua realização profissional, trazendo para o jovem uma certa sensação de frustração (OLIVEIRA, 2006).

Para que essa decepção não ocorra é necessário escolher o caminho a seguir levando em consideração de forma embasada. Essa escolha pode ser auxiliada fazendo-se uso de determinados critérios. Estudiosos têm se debruçado na tentativa de elencar os fatores levados em consideração no processo de escolha profissional. Soares (2002), por exemplo, destaca seis fatores que podem influenciar a escolha profissional do jovem: os fatores políticos, econômicos, sociais, educacionais, familiares e psicológicos, tais como destacados no Quadro 1.

Quadro 1 - Fatores significativos na escolha do curso superior.

\begin{tabular}{|l|l|}
\hline \multicolumn{1}{|c|}{ Fatores } & \multicolumn{1}{c|}{ Abrangência } \\
\hline Políticos & Política governamental e seu posicionamento perante a educação \\
\hline Econômicos & Mercado de trabalho, globalização, a empregabilidade da profissão \\
\hline Sociais & Busca do jovem em ascender socialmente \\
\hline Educacionais & $\begin{array}{l}\text { Falta de investimento em educação superior no Brasil, e as questões de escolha entre } \\
\text { universidade pública e privada }\end{array}$ \\
\hline Familiares & Desejo de realizar as expectativas dos pais no que se refere à vida profissional dos filhos \\
\hline Psicológicos & Interesses, motivações, e competências pessoais. \\
\hline
\end{tabular}

Fonte: Adaptado de Soares (2002).

Ainda neste aspecto, Morretto (2004) destaca que no processo de escolha do curso superior, os jovens são movidos pela expectativa de realização profissional e oportunidades no mercado de trabalho. Nesta mesma perspectiva, Biase (2008) constatou que fatores como mercado de trabalho e aspectos familiares são decisivos na escolha do curso superior. Nesta linha, Pinheiro e Santos (2010) averiguaram que no que se refere à escolha pelo curso de ciências contábeis, aspectos como prestígio profissional, ascensão para cargos diretivos, desenvolvimento pessoal e satisfação são normalmente relevantes no processo de decisão.

Sob foco semelhante, Valore e Cavallet (2012) também destacaram critérios utilizados para escolher a profissão, apresentando como principais fatores os gostos e afinidades pessoais dos estudantes, suas características e habilidades, as características do mercado, função social da empresa ou algum contato anterior com a área vivenciado pelos estudantes pesquisados. Ainda neste mesmo aspecto, Dias e Soares (2012) afirmam que os jovens levam em consideração, no processo de escolha profissional, o contexto familiar e universitário, bem como informações recebidas por outras pessoas quanto à carreira profissional pretendida. Assim, somando estes aspectos às suas necessidades pessoais o jovem toma sua importante decisão de qual carreira seguir. 


\subsection{Perfil do profissional contábil}

Inicialmente, faz-se necessário aludir às competências do profissional contábil mencionadas pelo American Institutes of CPA's (AICPA), apontadas no Quadro 2.

Quadro 2 - Principais competências do contador elencadas pela AICPA.

\begin{tabular}{|l|l|}
\hline \multicolumn{1}{|c|}{ Competências } & \multicolumn{1}{c|}{ Características } \\
\hline Funcionais & $\begin{array}{l}\text { Conhecimentos técnicos e práticos sobre modelos de tomada de decisões, análises de risco, } \\
\text { modelos de mensuração, técnicas de reporte, capacidade e técnica de pesquisa e a capacidade } \\
\text { de alavancar e usar tecnologia. }\end{array}$ \\
\hline Pessoais & $\begin{array}{l}\text { Desenvolver modelos de comportamento profissional, capacidade de resolver problemas e } \\
\text { tomar decisões, técnicas de relacionamento, liderança, comunicação, gerenciamento de proje- } \\
\text { tos e capacidade de alavancar e usar tecnologia. }\end{array}$ \\
\hline $\begin{array}{l}\text { Amplo Entendimento } \\
\text { de negócios }\end{array}$ & $\begin{array}{l}\text { Pensar de forma estratégica e crítica, ter conhecimentos segmentados por indústria, ter uma } \\
\text { perspectiva e entendimento global e internacional, conhecer técnicas de gerenciamento de } \\
\text { recursos, entender implicações legais e fiscais nos negócios, focalização em clientes e em } \\
\text { marketing, e a capacidade de alavancar e usar tecnologia. }\end{array}$ \\
\hline
\end{tabular}

Fonte: Adaptado de American Institute of CPAs - Core Competency Framework.

Antunes et al. (2005) também apresentam em seu estudo três competências específicas para o profissional contábil que são: conhecimentos específicos, habilidades e atitudes, conforme resumidas no Quadro 3.

Quadro 3 - Competências do contador.

\begin{tabular}{|l|l|}
\hline Competências & \multicolumn{1}{c|}{ Características } \\
\hline $\begin{array}{l}\text { Conhecimentos } \\
\text { específicos }\end{array}$ & $\begin{array}{l}\text { Práticas contábeis do Brasil e Internacionais; cenários de negócios, identificação, avaliação e geren- } \\
\text { ciamento de risco; avaliação de resultado e desempenho; estratégia e organização de negócios; } \\
\text { visão integrada da organização; ambiente legal e jurídico do país; aplicabilidade da tecnologia da } \\
\text { informação; gestão de projetos e de processos; identificação das necessidades de informação dos } \\
\text { usuários; auditoria; visão sistêmica da empresa; governança corporativa e aplicação das ferramen- } \\
\text { tas estatísticas e matemáticas. }\end{array}$ \\
\hline Habilidades & $\begin{array}{l}\text { Raciocínio lógico; visão estratégica dos resultados; percepção e aplicação interdisciplinar do co- } \\
\text { nhecimento; reflexão e análise crítica; comunicação verbal e escrita; auto avaliação; relacionamento } \\
\text { interpessoal e autocontrole. }\end{array}$ \\
\hline Atitudes & $\begin{array}{l}\text { Valores éticos; participação e comprometimento; visão crítica do mundo e dos negócios; autocríti- } \\
\text { ca; respeito ao próximo. }\end{array}$ \\
\hline
\end{tabular}

Fonte: Adaptador de Antunes et al. (2005).

Atividades como elaboração de relatórios gerenciais, planejamento tributário, contabilidade societária e procedimentos fiscais são apontadas como inerentes ao exercício da profissão contábil por Cardoso, Souza e Almeida (2006). Os mesmos autores apontam que além dessas atividades é necessário que o contador apresente habilidades como liderança, flexibilidade para mudanças, iniciativa, e bom relacionamento interpessoal. Nesse aspecto, Oliveira et al. (2011) verificaram que as empresas afirmaram buscar profissionais com iniciativa própria. Como principais rotinas e atividades exigidas estão elaboração de folha de pagamento e rotinas trabalhistas, apuração de impostos e escrituração fiscal e contábil.

As habilidades pessoais são uma das mais requeridas pelos empregadores, visto que estes procuram profissionais com liderança, proatividade, motivação, comunicação, comportamento ético, entre outros. No entanto, os conhecimentos específicos da área contábil, tributária e de auditoria, bem como habilidades e competências técnicas de interpretar cenários, avaliar processos e resultados e solucionar problemas não devem ser esquecidas (REIS et al. 2014). 


\subsection{Estudos Anteriores}

Sendo um dos primeiros trabalhos nesta abordagem, Cory (1992) verificou a percepção de calouros da universidade quanto ao profissional contábil. No entanto, em caminho antagônico ao da literatura brasileira, o estudo aponta um estereótipo negativo do contador. Mas, outros pesquisadores internacionais apontam uma percepção mais positiva sobre o profissional contábil tal como Germanou, Hassall e Tournas (2009) e Wessels e Steenkamp (2009).

Um dos principais estudos desta temática de pesquisa é o de Azevedo (2010). Por meio de uma foto questionário, técnica que mede a percepção por meio de representações gráficas (LUCA et al., 2011), o autor buscou verificar se os profissionais de contabilidade são estereotipados de maneira negativa pelo público externo à profissão. Os resultados apontam que os profissionais de contabilidade são mais percebidos como sendo do gênero masculino, mas que estes não são vistos de forma negativa pela população em nenhum dos aspectos referentes à criatividade, dedicação aos estudos, trabalho em equipe, comunicação, liderança, propensão ao risco e ética. Este estudo traçou o caminho para outras pesquisas, tais como Longo, Meurer e Oliveira (2014), Leal et al. (2014) e Roth et al. (2015), cujos resultados foram semelhantes ao encontrado por Azevedo (2010)

Em outro foco, Curty e Tavares (2014) procuraram verificar qual a imagem que profissionais da contabilidade possuem da sua própria profissão. Os resultados apontam que os contabilistas se consideram éticos e confiáveis e estão satisfeitos com a escolha que fizeram, no entanto, acreditam que a contabilidade deveria ser mais valorizada pela sociedade e que esta não tem o devido reconhecimento pelo trabalho realizado.

Os estudos citados até o presente momento verificaram o estereótipo do contador sob o prisma do público em geral, de estudantes universitários e dos próprios contadores. Mas, quanto aos estudantes do ensino médio? Como estes que estão prestes a escolher a carreira profissional a seguir enxergam o contabilista? A fim de responder estes questionamentos alguns estudos foram realizados. Nunes et al. (2014) verificou que os estudantes de ensino médio não conhecem as reais atribuições do contador, ligando este profissional à área de exatas. Em foco semelhante, Miranda, Miranda e Araújo (2013) perceberam que os estudantes ainda desconhecem aspectos relevantes inerentes à profissão, mas que esta não possui um prestígio menor quando comparada com profissões consideradas mais tradicionais.

No que tange a estudos internacionais, é possível citar o realizado por Cory, Martinez e Reeves (2010), onde foi constatado que o estereótipo negativo do profissional possui influência na relutância dos estudantes de ensino médio em escolher o curso para ingresso no ensino superior. Assim como os estudos nacionais apontaram que os discentes do ensino médio não possuem um amplo conhecimento do profissional contábil, Malthus e Fowler (2009) apresentaram resultado semelhante no contexto da Nova Zelândia. No entanto, diferentemente dos trabalhos brasileiros que apontam que esta falta de conhecimento não traz uma concepção negativa da profissão, o estudo supracitado afirma que os estudantes do ensino médio possuem uma ideia de que a profissão contábil é "chata" e maçante.

Em foco semelhante aos estudos citados, o presente trabalho procura, além de verificar o estereótipo quanto às características pessoais e atividades exercidas pelo contador, o estudo avança e diferencia-se dos demais realizados até o presente momento por verificar como os discentes enxergam o papel social do contador diante de aspectos como auxílio ao desenvolvimento do país, combate à corrupção e correta aplicação dos impostos.

\section{METODOLOGIA}

Trata-se de uma pesquisa descritiva, realizada através da metodologia de survey. O questionário adotado no trabalho foi elaborado com base na revisão de literatura e dos estudos anteriores. Após a elaboração do instrumento de pesquisa procedeu-se o pré-teste com quinze estudantes 
do ensino médio. Este procedimento permitiu que o pesquisador visualizasse possíveis problemas com o questionário (HAIR et al. 2014).

Após a realização do pré-teste, o questionário foi ajustado e enviado para quatro doutores com pesquisas na área de educação contábil (especialistas), que revisaram o instrumento de pesquisa e fizeram sugestões de melhoria. Após a realização das modificações preconizadas, procedeu-se um novo teste do formulário de pesquisa concluindo assim a fase de validação do questionário. A Figura 1 sumariza as etapas aqui explanadas.

Figura 1 - Etapas para validação do questionário

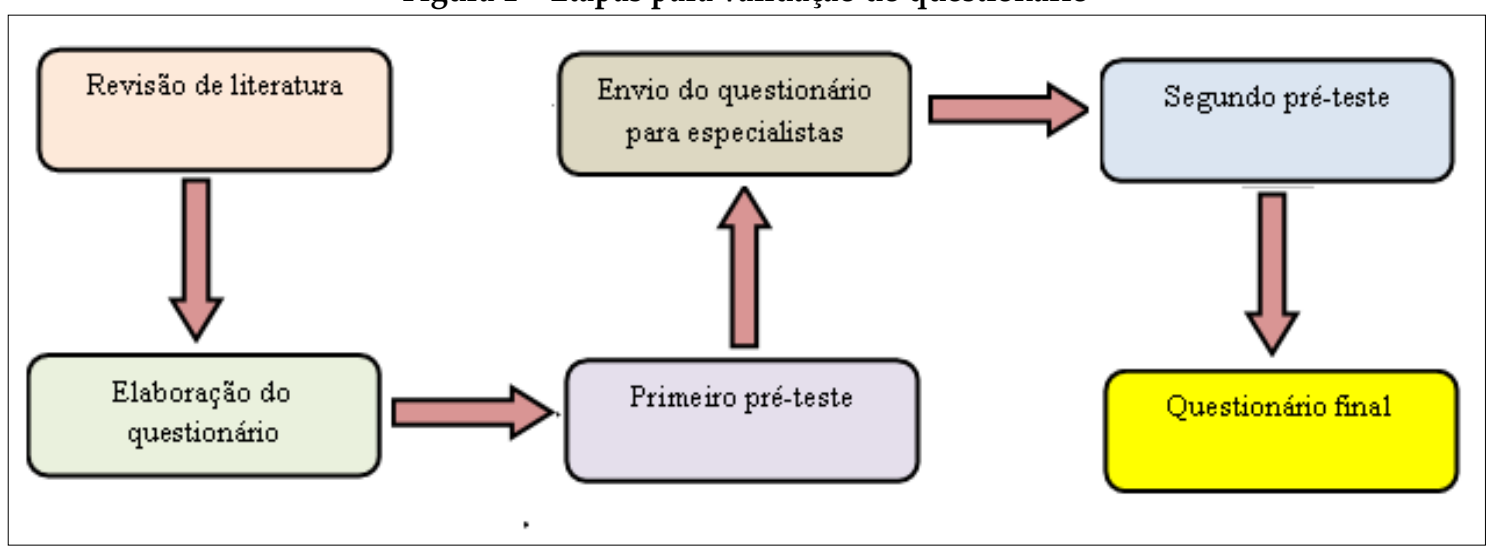

Fonte: Elaboração própria.

O questionário foi dividido em duas seções: a primeira verificava o perfil do respondente e a segunda procurava investigar a percepção dos respondentes quanto às características pessoais, profissionais e sociais do contador. O Quadro 3 traz um resumo do questionário.

Quadro 3 - Resumo do questionário aplicado.

\begin{tabular}{|c|c|c|}
\hline Bloco & Temática & Questões \\
\hline Primeiro & Perfil do respondente & $\begin{array}{l}\text { - Gênero: ( ) Masculino ( ) Feminino } \\
\text { - Idade: ( ) Menos de } 15 \text { anos ( ) Entre } 15 \text { e } 18 \text { anos ( ) Mais de } 18 \text { anos. } \\
\text { - Série: ( ) } 1^{o} \text { ano, ( ) 20 ano; ( ) } 3^{0} \text { ano. } \\
\text { - Renda Familiar ( ) Menos de } 1 \text { salário mínimo; ( ) entre } 1 \text { e } 3 \text { salários } \\
\text { mínimos; ( ) entre } 4 \text { e } 5 \text { salários mínimos; ( ) Entre } 6 \text { e } 8 \text { salários mí- } \\
\text { nimos; ( ) mais de oito salários mínimos. } \\
\text { - Já assistiu algum filme/novela/seriado/desenho que apresentou um } \\
\text { contador como personagem ( ) sim, ( ) não, ( ) não sei/não lembro. } \\
\text { - Conhece algum profissional da área contábil ( ) sim, um parente, ( ) } \\
\text { sim, um amigo ou colega, ( ) sim, conheço alguém mas não é um ami- } \\
\text { go ou colega, ( ) não sei/não conheço. } \\
\text { - Trabalhar na área contábil é uma opção ( ) sim, ( ) não, ( ) não } \\
\text { sei/não tenho certeza } \\
\text { - Área profissional que pretende seguir. ( ) sim, ( ) não; ( ) ainda } \\
\text { tenho dúvidas. }\end{array}$ \\
\hline \multirow{3}{*}{ Segundo } & $\begin{array}{l}\text { Percepção sobre as caracte- } \\
\text { rísticas pessoais do contador }\end{array}$ & $\begin{array}{l}\text { Gosta de rotinas, é muito matemático, é preciso e focado, é organizado, } \\
\text { gosta de burocracia, é honesto, é inteligente e criativo. }\end{array}$ \\
\hline & $\begin{array}{l}\text { Percepção sobre as ativida- } \\
\text { des profissionais do conta- } \\
\text { dor }\end{array}$ & $\begin{array}{l}\text { Realiza os cálculos dos impostos, faz análises financeiras, realiza ativida- } \\
\text { des repetitivas, cumpre normas e regras, auxilia o administrador, elabora } \\
\text { as demonstrações financeiras, elabora a folha de pagamento, faz a decla- } \\
\text { ração do imposto de renda, facilita o trabalho do governo, analisa os } \\
\text { custos das empresas, auxilia a empresa a tomar decisões, faz a abertura e } \\
\text { fechamento das empresas. }\end{array}$ \\
\hline & $\begin{array}{l}\text { Percepção sobre o papel } \\
\text { social do contador }\end{array}$ & $\begin{array}{l}\text { É bastante reconhecido e valorizado pela sociedade, alerta as empresas } \\
\text { sobre mudanças no mercado, é bem remunerado, é importante para o } \\
\text { desenvolvimento do país, é capaz de ajudar a diminuir a corrupção no } \\
\text { país, é capaz de ajudar o governo a aplicar bem os impostos. }\end{array}$ \\
\hline
\end{tabular}


O segundo bloco do questionário foi apresentado através da escala Likert de cinco pontos, onde (1) significa discordo totalmente, (2) discordo em parte, (3) indiferente, (4) concordo em parte e (5) concordo totalmente. A escala de cinco pontos foi adotada visto que, de acordo com Vieira e Dalmoro (2008) apresenta precisão semelhante com a de sete pontos e ao mesmo tempo torna a coleta de dados mais rápida.

O questionário foi aplicado em uma escola pública estadual situada na cidade de Jaboatão dos Guararapes, na região metropolitana do Recife - Pernambuco. A escolha da escola deu-se por conveniência de acesso aos estudantes. As turmas do primeiro ao terceiro ano participaram da pesquisa. Quanto ao tamanho da amostra, adotou-se o critério de Barbetta (2002) utilizado quando não se conhece o total do universo a ser pesquisado, apresentado Equação 1.

$$
\mathrm{N}_{0}=1 / \mathrm{E}^{2}
$$

Em que,

No é o tamanho da amostra;

E² é o erro amostral tolerável, que para a presente pesquisa adotou-se como sendo de $10 \%$.

Salienta-se que, conforme apontado por Ambrosano et al. (2011), muitas vezes adotar o erro amostra de $5 \%$ pode superestimar a amostra, aumentando desnecessariamente os custos envolvidos com a pesquisa. Diante destes parâmetros e de sua aplicação na fórmula, a amostra mínima que deveria ser utilizada no estudo é de 100 participantes, sendo que a pesquisa pôde contar com 112 questionários válidos.

Após a coleta dos dados, estes foram tabulados em uma planilha Excel. Em seguida procedeu-se a análise descritiva dos dados. Após estes procedimentos, auferiu-se o alfa de Cronbach a fim de verificar a confiabilidade interna do questionário e o teste de fator único de Harman que aponta possíveis vieses na forma de coleta dos dados. Em seguida, verificou-se, através do teste Qui-quadrado, possíveis relações entre o perfil dos respondentes e a percepção destes quanto ao profissional contábil. Todas as análises foram realizadas no SPSS v. 20.

\section{RESULTADOS DA PESQUISA}

\subsection{Análise do Perfil}

Inicialmente, foi analisado o perfil dos estudantes que responderam ao formulário de pesquisa a fim de conhecer as características dos entrevistados. Verificou-se 56,30\% dos entrevistados gênero feminino. Ao mesmo tempo, 85,7\% dos discentes estão na faixa dos 15 aos 18 anos. Voltando aos dados da presente pesquisa, 31,2\% dos entrevistados estavam na primeira série do ensino médio, $18,8 \%$ no segundo ano e $50 \%$ no terceiro ano. Quanto à faixa de renda, $75,9 \%$ dos entrevistados possuem renda entre 1 e 3 salários mínimos.

Quanto ao contato com a profissional contábil, averiguou-se que 41,1\% dos discentes já haviam assistido filme que destacava algum personagem da área contábil. Ao mesmo tempo, 52,7\% disseram não conhecer algum profissional de contabilidade sendo que apenas $17 \%$ afirmou ter um parente, $8 \%$ possuem um amigo e 22,3\% conhecem alguém do seu ciclo de relacionamentos que é da área contábil.

No que se refere a considerar a contabilidade uma área profissional a seguir, 42,9\% afirmaram que não escolheriam a profissão; 33,9\% afirmaram que não possuem certeza se optariam pela área, enquanto $23,2 \%$ destacaram a intenção de fazer ciências contábeis. Constatou-se que dentre os alunos do $3^{\text {o }}$ ano apresentou-se um maior percentual de discentes que não querem seguir a carreira contábil, conforme ilustrado no Gráfico 1. 


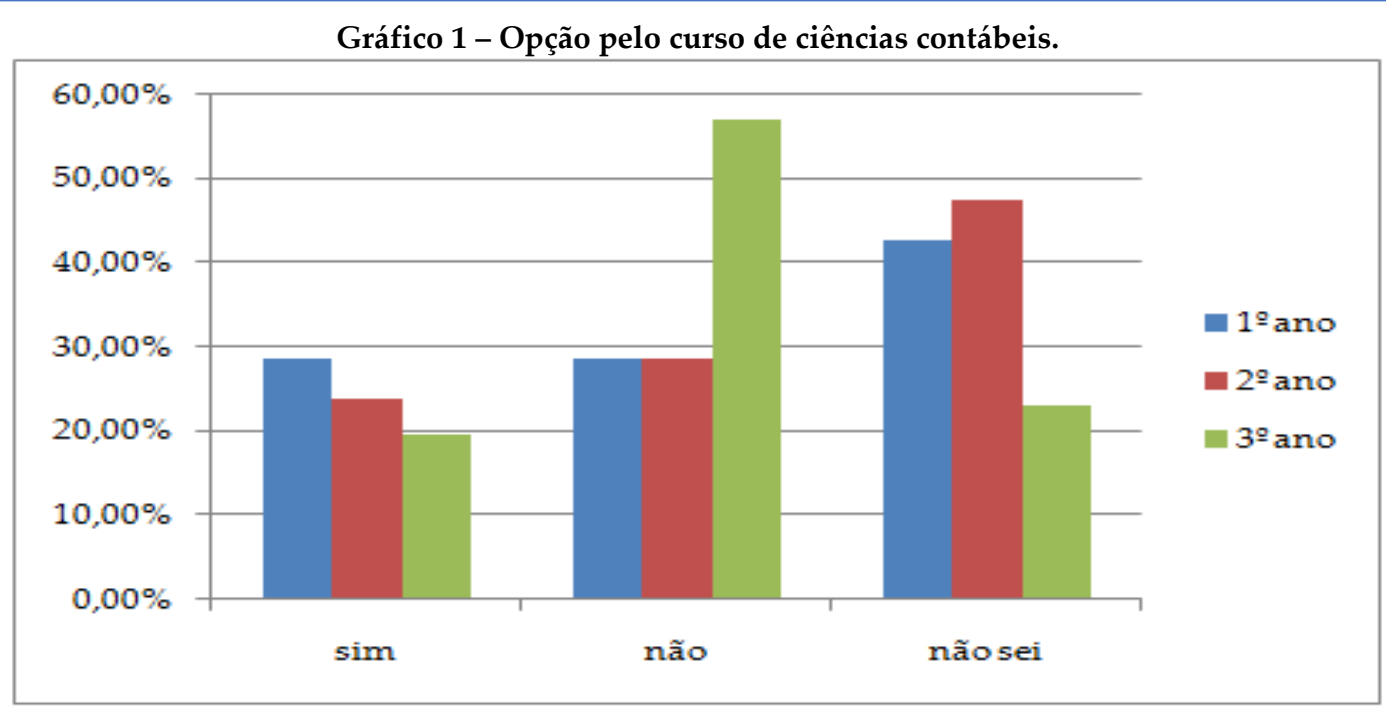

Fonte: Dados da pesquisa.

Ainda sobre a escolha profissional, foi verificado que $66,1 \%$ dos estudantes afirmam já ter escolhido a área que pretendem seguir. As áreas com mais atraíram os discentes foram direito (13\%), engenharia e medicina (10\% cada), psicologia ( $8 \%)$, administração $(7 \%)$ e jornalismo (6\%), confirmando os achados de Barreto e Aiello (2007), Valore e Cavallet (2012), Aquino (2015) e Tokarnia (2015). Após esse primeiro bloco de perguntas, o instrumento de pesquisa dirigiu os respondentes para refletirem sobre determinadas características a fim de verificar se na opinião deles os aspectos mencionados se enquadravam ou não no perfil do profissional contábil.

Quanto aos aspectos sociais que norteiam a profissão contábil, inicialmente foi apresentado que o profissional contábil é bastante reconhecido e valorizado pela sociedade sendo que 40,18\% concordam com essa assertiva (3,57\% concordam totalmente e $36,61 \%$ concordam em parte) e $33,04 \%$ discordam da afirmação (8,93\% discordam totalmente e $24,11 \%$ discordam em parte). Como reflexo desse resultado, temos que $55,36 \%$ dos respondentes acreditam que os contabilistas são bem remunerados. Esses achados possuem relação visto que, por vezes, o ser bem remunerado tem sido colocado como sinônimo de ser valorizado.

Verificou-se também que 66,07\% dos estudantes acreditam que o profissional contábil é capaz de alertar as empresas sobre possíveis mudanças no mercado (38,39\% concordam totalmente e $27,68 \%$ concordam em parte). Ainda neste aspecto social, $79,46 \%$ dos respondentes consideram o contabilista importante para o desenvolvimento do país $(49,11 \%$ concordam totalmente enquanto $30,36 \%$ concordam em parte). $63,39 \%$ concordam que o profissional da área contábil é capaz de ajudar o governo a aplicar bem os impostos.

Resultado também interessante de ser destacado é o fato de 47,32\% dos estudantes afirmarem que o contador pode ajudar a diminuir a corrupção no país. Esta ilação foi encontrada no presente trabalho, mesmo após o maior caso de corrupção na história do país, que colocou à prova auditores contábeis (FILGUEIRAS, 2015) e teve a provável participação de um contador envolvido nos casos de mensalão e enriquecimento ilícito de um determinado senador (VALENTE, 2015). O que parece é que, ou a percepção dos estudantes não muda independente dos fatos noticiados, ou que os casos apresentados pela mídia não são compreendidos ou conhecidos de forma ampla pelos estudantes pesquisados.

No que tange às atividades realizadas pelo contador, verificou-se que $82,14 \%$ dos discentes entendem que o contador realiza os cálculos dos impostos, bem como auxilia o administrador da organização, 90,18\% acreditam que este profissional faz análise e elabora demonstrações financeiras. A análise de custos da empresa também foi apontada pela maioria dos estudantes como uma atividade do contabilista (84,82\%). Ressalta-se, ainda, que 78,57\%, 70,54\% e 68,75\% dos responden- 
tes, respectivamente, acreditam que faz parte do quadro de atividades exercidas pelo profissional contábil a elaboração de folha de pagamento, declaração do imposto de renda e apoio no processo de tomada de decisão nas empresas.

Destaca-se, neste aspecto, que apenas $43,75 \%$ dos estudantes associam o processo de abertura e fechamento das empresas ao contador. Este dado pode denotar que os jovens e adolescentes entrevistados não possuem uma compreensão ampla dos procedimentos necessários para se iniciar um negócio no contexto brasileiro. Ainda foi apresentado que, na opinião dos entrevistados, o contador realiza atividades repetitivas $(60,71 \%)$ e é uma profissão pautada no cumprimento de muitas normas e regras $(66,07 \%)$.

Quanto às características pessoais do profissional contábil temos que 56,25\% dos estudantes consideram o contabilista inteligente e criativo, 41,07\% acreditam que esses profissionais são honestos e que gostam de rotinas foi uma característica apontada por $41,96 \%$ dos respondentes. Ressalta-se ainda que $49,11 \%$ discordaram com a assertiva de que o contabilista é tímido e $58,04 \%$ discordaram da afirmação de que esse profissional é pouco comunicativo, além de $42,86 \%$ não concordarem com a indicação de que os contadores gostam de burocracia.

Resultados interessantes ainda são encontrados quando destacado que 87,50\% dos respondentes consideraram o contador um profissional focado, $86,61 \%$ o consideram organizado $(60,71 \%$ concordam totalmente). Destaca-se ainda que, semelhante ao apresentado por Nunes et al. (2014) de que os discentes veem o profissional contábil como sendo da área de exatas, os estudantes participantes desta pesquisa consideravam o profissional contábil muito matemático $(90,18 \%$ concordam com a assertiva, sendo que $66,07 \%$ concordam totalmente).

Diante desses aspectos iniciais, é possível perceber que a percepção dos estudantes quanto ao profissional contábil é de certa forma positiva. Visto que aspectos negativos como timidez e pouca comunicação foram rejeitados pela maioria dos respondentes como relacionados a este tipo de profissional, ao mesmo tempo que atributos positivos como foco, organização tiveram a maior concordância por parte dos discentes que ainda destacaram o contador como importante para o desenvolvimento do país.

\subsection{Análise Inferencial}

Inicialmente, foi averiguada que o alfa de Cronbach referente ao questionário do presente estudo foi de 0,834 o que apresenta uma boa confiabilidade para o instrumento de pesquisa. Observou-se que algumas características do perfil dos discentes podem exercer influência na percepção destes quanto ao profissional contábil e suas atribuições. Percebeu-se que o gênero foi significativo em dois aspectos: entender que o contador participa do processo de abertura de empresas, bem como que o mesmo é importante no combate à corrupção.

No que se refere ao processo de abertura de empresas ( $x^{2} 11,944$, valor-p 0,018$)$, temos que as estudantes tendem a perceber mais o papel do profissional contábil nesta atividade, visto que 49,2\% das respondentes indicaram concordância de que esta atividade está relacionada ao trabalho do contador, enquanto 39,7\% dos estudantes apresentaram a mesma percepção. Nesta mesma perspectiva, os 40,8\% dos estudantes afirmaram que esta atividade não faz parte do escopo de trabalho do contador, enquanto $30,2 \%$ das discentes responderam da mesma forma.

Quanto ao entendimento de que o contador é importante no combate à corrupção $\left(x^{2} 23,33\right.$, valor-p 0,000), tem-se que as moças apresentaram uma percepção mais positiva neste quesito. $63,5 \%$ concordaram com a assertiva em detrimento de $26,5 \%$ dos rapazes que apresentaram a mesma opinião. Esses resultados são resumidos na Tabela 1. 
Tabela 1 - Influência do gênero na percepção dos respondentes.

\begin{tabular}{l|c|c|c}
\hline \multicolumn{1}{c|}{ Assertiva } & $\begin{array}{c}\text { Resultado Qui- } \\
\text { quadrado }\end{array}$ & $\begin{array}{c}\text { Concordância } \\
\text { (Masculina) }\end{array}$ & $\begin{array}{c}\text { Concordância } \\
\text { feminina }\end{array}$ \\
\hline Faz a abertura de empresas & $\mathrm{x}^{2} 11,944$, valor-p 0,018 & $39,7 \%$ & $49,2 \%$ \\
\hline É capaz de ajudar a diminuir a corrupção no país & $\mathrm{x}^{2} 23,33$, valor-p 0,000 & $26,5 \%$ & $63,5 \%$ \\
\hline
\end{tabular}

Fonte: Dados da pesquisa.

A idade foi significativa na compreensão de que o profissional contábil é responsável por elaborar a declaração do imposto de renda ( $x^{2} 15,853$; valor-p 0,045$)$. Obteve-se o resultado de que os estudantes mais velhos (acima de 18 anos) avaliaram com maior ênfase que esta atividade está ligada ao exercício profissional do contabilista (83,30\% concordam com a assertiva).

No que se refere ao contador auxiliar no processo de tomada de decisões ( $x^{2}$ 17,812; valor-p $0,023)$, os alunos do terceiro ano se apresentaram como mais propensos a concordarem com a afirmação, visto que $76,80 \%$ destes estudantes concordaram com a assertiva, enquanto apenas $10,7 \%$ discordaram. Por outro lado, $28,6 \%$ dos discentes do primeiro ano do ensino médio apresentaram a percepção de que o contador não auxilia na tomada de decisão empresarial, tal como apontado no estudo de Miranda, Miranda e Araújo (2013). No entanto, a série não se mostrou significativa em outras variáveis o que não permite inferir que a percepção dos jovens quanto ao profissional contábil amadurece à medida que estes avançam em seus estudos.

A renda familiar se apresentou como significativa no que tange à percepção de que o profissional contábil é bem remunerado ( $x^{2} 28,143$; valor-p 0,30 ). Constatou-se que os estudantes com menores níveis de renda qualificam o contador como um profissional bem remunerado. $62,5 \%$ dos discentes com renda menor que um salário mínimo e $60 \%$ dos que possuem rendimento entre 1 e 3 salários mínimos possuem a opinião de que o contador é bem remunerado.

Em contrapartida, $41,7 \%$ dos discentes com renda entre 4 e 5 salários, $20 \%$ dos que possuem renda entre 5 e 8 salários mínimos e nenhum dos que possuem acima de 8 salários mínimos possuem a mesma opinião. Pode-se compreender que à medida que a renda familiar do jovem cresce, menos atrativo se torna o salário do profissional contábil que ainda pode ser considerado baixo diante da remuneração oferecida por outras carreiras (MIRANDA; MIRANDA; ARAÚJO, 2013)

Por fim, a percepção de que o contador realiza um trabalho repetitivo foi influenciada pelo fato do discente conhecer ou não a área que pretendem atuar $\left(x^{2} 18,831\right.$; valor-p 0,016$)$. Verificou-se que $71,90 \%$ dos estudantes que ainda não escolheram a área em que irão atuar assumem uma opinião de que o contador realiza muitas atividades repetitivas, enquanto $21,62 \%$ que já estão decididos apresentam a mesma opinião. Quanto aos demais aspectos apresentados no questionário, estes não apresentaram relação significativa com as variáveis do perfil e, portanto, não foram destacados na presente seção. Com isto, o trabalho segue para seu capítulo conclusivo.

\section{CONSIDERAÇÕES FINAIS}

O objetivo do presente estudo foi verificar a percepção de estudantes do ensino médio, prestes a escolher o curso universitário, sobre o profissional contábil. Sabe-se que estes jovens estão em um momento decisivo em suas vidas, sendo que a contabilidade é uma das áreas prováveis de escolha destes estudantes para sua carreira profissional.

No presente estudo foi apontada uma percepção positiva por parte dos respondentes em relação ao profissional contábil. Os principais resultados do estudo destacam que 40,18\% dos jovens respondentes acreditam que o profissional contábil é bastante reconhecido e valorizado pela sociedade. Ainda se destaca o fato de que 55,36\% dos respondentes acreditam que os contabilistas são bem remunerados, no entanto, à medida que a renda familiar dos estudantes cresce, diminui a concordância com este aspecto, o que pode ser explicado pelo fato do salário do profissional contábil ainda encontrar-se em patamar inferior aos de outras profissões. 
Ressalta-se que 79,46\% dos respondentes consideram o contabilista importante para o desenvolvimento do país, bem como para $63,39 \%$ dos estudantes o profissional da área contábil é capaz de ajudar o governo a aplicar bem os impostos, ao mesmo tempo que 47,32\% dos estudantes apontam que o contador pode ajudar a diminuir a corrupção no país. A maioria dos estudantes entrevistados entende que o contador realiza atividades como cálculos dos impostos, análise de custos, elaboração de folha de pagamento, declaração do imposto de renda. Destacam também a compreensão de que este profissional apoia o processo de tomada de decisão nas empresas e elaboração de demonstrações financeiras.

Quanto às características pessoais do contador, os estudantes enxergam nesse profissional, atributos como inteligência, criatividade e honestidade. Confirmou-se também neste estudo, assim como outros realizados anteriormente, que o contador ainda está ligado à figura de um matemático, ou a um profissional da área de exatas. Apesar da percepção dos discentes analisados para com o profissional contábil ter sido boa, ressalta-se que $42,9 \%$ não escolheriam a profissão, sendo que, assim como nos trabalhos anteriores, as áreas que mais atraem são direito, engenharia e medicina, ou seja, os cursos tradicionais. Uma provável explicação para esse resultado ainda pode estar relacionada ao salário oferecido, bem como a própria percepção que os respondentes apresentaram de que o profissional contábil realiza atividades repetitivas o que pode não ser muito atrativo na faixa etária dos respondentes.

Acredita-se que o trabalho alcançou seus objetivos e que este contribuiu para uma melhor compreensão da forma como os discentes do ensino médio percebem esse profissional. Aponta-se a necessidade de uma maior aproximação da academia às instituições de ensino médio, permitindo que estudantes de ciências contábeis visitem os estudantes mais jovens, tirando suas dúvidas e trazendo uma maior clareza do que realmente é estudar ciências contábeis. Relevante seria também que os próprios profissionais interagissem com os discentes do ensino médio, apontando as vantagens de escolher a área, perspectivas de crescimento, bem como outros aspectos que possam permitir uma melhor compreensão deste ramo profissional, podendo até mesmo tornar a carreira mais atrativa para estes jovens.

Como sugestão para estudos futuros recomenda-se, então, aumentar a amostra do presente trabalho, bem como verificar quais fatores levam ao fato de boa parte dos discentes não apontar a contabilidade como a área escolhida para suas carreiras profissionais, mesmo estes apresentando uma percepção positiva quanto à profissão. Interessante também é comparar a percepção de discentes do ensino público e privado, verificar possíveis diferenças entre a opinião de estudantes das áreas centrais da cidade e do subúrbio.

\section{REFERÊNCIAS}

AMERICAN INSTITUTE OF CPAs. Core Competency Framework. Disponível em: http://www.aicpa.org/interestareas/accountingeducation/resources/pages/corecompetency.aspx. Acesso em: 06 set. 2015.

ANTUNES, M. T.; MORAIS, J. F.; FORMIGONI, H. LEITE, R.S. Tecnologias educacionais em Cursos de Contabilidade Avaliados no Exame Nacional de Cursos (ENC/2003) com Conceitos A e B. Contabilidade, Gestão e Governança, v. 8, n. 1, 2005.

AQUINO, Y. Medicina foi curso mais procurado no Sisu; resultado está disponível. EBC. 15 de junho de 2015. Disponível em: http://www.ebc.com.br/educacao/2015/06/mec-inscreve-quase-12milhao-de-candidatos-para-segunda-edicao-do-sisu-2015. Acesso em: 02 set. 2015. 
AZEVEDO, R. F. L. A percepção pública sobre os contadores: "bem ou mal na foto"? Universidade de São Paulo, Mestrado em Ciências Contábeis (Dissertação). São Paulo, 2010.

BARBETTA, P. A. Estatística aplicada às Ciências Sociais. 5 ed. Florianópolis: UFSC, 2002.

BARRETO, M. A.; AIELLO-VAISBERG, T. Escolha Profissional e Dramática do Viver Adolescente. Psicologia \& Sociedade, v. 19, n. 1, p. 107-114, 2007.

CARDOSO, J.L.; SOUZA, M.A. ALMEIDA, L.B. Perfil do contador na atualidade: Um estudo exploratório. Revista de Administração e Contabilidade da UNISINOS, v. 3, n. 3, p. 275 -284, 2006.

CHADE, J. Caso Petrobrás concorre a 'prêmio' de maior escândalo de corrupção do mundo. Estadão. Publicado em 09 de dezembro de 2015. Disponível:

http://politica.estadao.com.br/noticias/geral,escandalo-na-petrobras-concorre-a-premio-de-maiorescandalo-de-corrupcao-do-mundo,10000004309. Acesso em: 27 dez. 2015.

CORY, S. N. Quality and Quantity of Accounting Students and the Stereotypical accountant: is there a relationship? Journal of Accounting Education, v. 10, p. 1-24, 1992.

CORY, S. N.; MARTINEZ, G.; REEVES, T. E. African American High School Students' perceptions of accountants. Small Business Association of Jamaica, v. 10, n. 1, p. 17-37, 2010.

CURTY, N. A. P.; TAVARES, T. A imagem dos contadores sobre sua profissão e a Teoria das Representações Sociais: um estudo empírico na cidade de Londrina e região. Anais... 5. Congresso UFSC de Controladoria e Finanças, Santa Catarina, 2014.

DIAS, M. S. L.; SOARES, D. H. P. A Escolha Profissional no Direcionamento da Carreira dos Universitários. Psicologia: Ciência e Profissão, v. 32, n. 2, p. 272-283, 2012.

ECONOMIA UOL. Brasil cobre muito imposto, mas usa mal os recursos. Uol. Publicado em 25 de julho de 2012. Disponível em: http://economia.terra.com.br/brasil-cobra-muito-imposto-mas-usamal-os-recursos,b25877561f66b310VgnCLD200000bbcceb0aRCRD.html. Acesso em: 27 dez. 2015.

EHRLICH, I. F; CASTRO, F.; SOARES, D. H. P. Orientação Profissional: liberdade e determinantes da escolha profissional. Revista de Ciências Humanas, n. 28, p. 61-79, 2000.

FILGUEIRAS, M. L. Escândalo da Petrobras põe os auditores na berlinda. Exame. Publicado em 04 de março de 2015. Disponível em: http://exame.abril.com.br/revistaexame/edicoes/1084/noticias/dava-pra-pegar. Acesso em: 20 fev. 2016.

GERMANOU, E.; HASSAL, T.; TOURNAS, Y. Students' perceptions of accounting profession: work value approach. Asian Review of Accounting, v. 17, n. 2, p. 136-148, 2009.

HAIR JR., J. F.; CELSI, M. W.; ORTINAU, D. J.; BUSH, R. P. Fundamentos de Pesquisa de Marketing. 3 ed. Porto Alegre: AMGH Editora Ltda, 2014. 
JORDANI; P. S.; BARICHELO; R.; ARTMANN; C. R.; ECKER; J. S. Fatores determinantes na escolha profissional: um estudo com alunos concluintes do ensino médio da região Oeste de Santa Catarina. Revista ADMpg Gestão estratégica, Ponta Grossa, v. 7, n. 2, p. 25-32, 2014.

LEAL, E. A.; MIRANDA, G. J.; ARAÚJO, T. S.; BORGES, L. F. Estereótipos na Profissão Contábil: a opinião de estudantes e do público externo no Triângulo Mineiro. Contabilidade, Gestão e Governança, v. 17, n. 1, p. 134-153, jan./abr. 2014.

LONGO, I.M.; MEURER, A.; OLIVEIRA, M.R. A Imagem do Contador pela Percepção Pública: um Estudo sobre o Nível de Estereotipagem acerca destes Profissionais. Anais... In: Congresso UFSC de Controladoria e Finanças, 5., Santa Catarina, 2014.

MALTHUS, S. FOWLER, C. Perceptions of accounting: a qualitative New Zealand study. Pacific Accounting Review, v. 21, n. 1, p. 26-47, 2009.

MIRANDA, C. S.; MIRANDA, R. A. M.; ARAÚJO, A. M. P. Percepções dos Estudantes do Ensino médio sobre o curso de ciências contábeis e as atividades do profissional contador. Revista de Gestão, Finanças e Contabilidade, Salvador, v. 3, n. 1, p. 17-35, jan/abr., 2013.

NUNES, I. V.; SILVA, T. D.; MIRANDA, G. J.; LEAL, E. A. A percepção dos estudantes de ensino médio sobre as responsabilidades de um contador. Revista Universo Contábil, Blumenau, v. 10, n. 4, p. 144-161, out./dez., 2014

OLIVEIRA, C. R.; GOMES, G.; CUNHA, P.R.; RAUSCH, R.B. Aproximações entre o Perfil do Contador Desejado pelo Mercado e as Matrizes Curriculares de Cursos de Graduação em Ciências Contábeis. Anais... In: Encontro de Ensino e Pesquisa em Administração e Contabilidade, 3., João Pessoa, Paraíba, 2011.

OLIVEIRA, M. H. D. Uma Escolha Profissional Equivocada como Geradora de Crise no Jovem Universitário. Mestrado em Psicologia Social (Dissertação), Universidade Federal de Minas Gerais, Belo Horizonte, 2006.

PEREIRA, N. A.; MORUA, M. F.; MIRANDA, G. J.; MEDEIROS, C. R. O. Herói ou vilão? Mudanças no estereótipo dos contadores na produção cinematográfica. Anais... In: Congresso Anpcont, 8., Rio de Janeiro, 2014.

REIS, A. O.; MOREIRA, V. S.; SEDIYAMA, G. A. S.; MOREIRA, C. C. Perfil do profissional Contábil: Habilidades, competências e Imagem simbólica. Anais... In: Congresso USP de Controladoria e Contabilidade, 8., São Paulo, 2014.

ROTH, T. C.; MURRO, E. V. B.; TEIXEIRA, G. B.; VOESE, S. B. Inteligências Múltiplas e o estereótipo do contador. Revista Ambiente Contábil, Natal, v. 7, n. 1, p. 132 - 154, jan./jun. 2015.

SOARES, D. H. P. A escolha profissional: do jovem ao adulto. 2 ed. São Paulo: Summus, 2002.

TOKARNIA, M. Administração, direito e medicina são os cursos mais procurados no Sisu. Uol Educação, 22 de janeiro de 2015. Disponível em:

http://educacao.uol.com.br/noticias/2015/01/22/administracao-direito-e-medicina-sao-os-cursosmais-procurados-no-sisu.htm. Acesso em: 02 set. 2015. 
VALENTE, R. Trajetória de contador é ligada a suspeitos em casos de corrupção. Folha Online. Publicado em 13 de julho de 2015. Disponível em:

http://www1.folha.uol.com.br/poder/2015/07/1654855-trajetoria-de-contador-e-ligada-a-suspeitosem-casos-de-corrupcao.shtml. Acesso em: 20 fev. 2016.

VALORE, L. A.; CAVALLET, L. H. R. Escolha e Orientação Profissional de Estudantes de Curso Pré-Vestibular Popular. Psicologia \& Sociedade, v. 24, n. 2, p. 354-363, 2012.

WESSELS, P.L.; STEENKAMP, L.P. An Investigation into Students' perceptions of accountants. Meditari Accountancy Research, v. 17, n. 1, p. 117-132, 2009.

COTRIN; A. M.; SANTOS; A. L.; ZOTTE JUNIOR; L. A evolução da contabilidade e o mercado de trabalho para o contabilista. Revista Conteúdo, Capivari, v. 2, n. 1, jan./jul. 2012.

LUCA; M. M. M.; CORNACHIONE JUNIOR; E. B; CUNHA; J. V. A.; OTT; E. Associação dos modelos de sucesso profissional e gênero entre graduandos de ciências contábeis. Advances in Scientific and Applied Accounting, São Paulo, v. 4, n. 2, p. 263-284, 2011.

PINHEIRO; R. G.; SANTOS, M. R. Fatores de escolha pelo curso de Ciências Contábeis - uma pesquisa com os graduandos na Capital e Grande São Paulo. Anais... In: Seminários de Administração, São Paulo, 2010.

VEIRA; K.M.; DALMORO; M. Dilemas na Construção de Escalas Tipo Likert: o Número de Itens e a Disposição Influenciam nos Resultados?. Anais... In: Encontro da ANPAD, 32., Rio de Janeiro, 2008.

AMBROSANO, G. M. B.; GONÇALVES, J. R.; PEREIRA, A. C.; MENEGHIN, M.; PARDI, V.; PEREIRA, S. M. Dimensionamento de Amostras e Análise Economica em Levantamento Epidemiologico de Cárie. Resumo expandido, In: Reunião Anual da SBPC, 63. 2011. 